\title{
Malocclusion and socioeconomic indicators in primary dentition
}

\section{Raulison Vieira de Sousa(a) Ana Karla de Almeida Pinto-Monteiro(b) Carolina Castro Martins ${ }^{(c)}$ Ana Flávia Granville-Garcia ${ }^{(a)}$ Saul Martins Paiva ${ }^{(c)}$}

(a) Department of Pediatrics, School of Dentistry, Universidade Estadual da Paraíba - UEPB, Campina Grande, PB, Brazil.

(b) Department of Orthodontics, School of Dentistry, Universidade do Estado do Rio Grande do Norte - UERN, Caicó, RN, Brazil.

(c) Department of Pediatrics, School of Dentistry, Universidade Federal de Minas Gerais - UFMG, Belo Horizonte, MG, Brazil.

Declaration of Interests: The authors certify that they have no commercial or associative interest that represents a conflict of interest in connection with the manuscript.

Corresponding Author:

Ana Flávia Granville-Garcia

E-mail: anaflaviagg@hotmail.com

htrp://dx.doi.org/10.1590/S1806-83242013005000032 Epub Dec 02, 2013

Submitted: Mar 17, 2013

Accepted for publication: Sep 01, 2013

Last revision: Sep 14, 2013
Abstract: The aim of the present study was to determine the prevalence of malocclusion and associations with socioeconomic indicators among preschoolers. A cross-sectional study was conducted with 732 children 3 to 5 years of age in the city of Campina Grande, Brazil. Three dentists underwent a calibration exercise $(\mathrm{K}=0.85-0.90)$ and diagnosed malocclusion based on the criteria proposed by Foster \& Hamilton and Grabowski et al. Parents/guardians answered a questionnaire addressing sociodemographic aspects. Data analysis involved descriptive statistics and bivariate Poisson regression (PR; $\alpha=5 \%$ ). The prevalence of malocclusion was $62.4 \%$. The most frequent types were increased overjet (42.6\%), anterior open bite (21\%) and deep overbite (19.3\%). An association was found between malocclusion and age: the prevalence of malocclusion was greater among younger children, with the highest prevalence among 3-year-olds ( $\mathrm{PR}=1.116 ; 95 \% \mathrm{CI}=1.049-1.187)$. The prevalence of malocclusion was high. Mother's schooling and household income were not associated with malocclusion. Socioeconomic factors were also not associated with the occurrence of malocclusion.

Descriptors: Malocclusion; Socioeconomic Factors; Income; Child; Overbite.

\section{Introduction}

From a public health perspective, the assessment of malocclusion in the deciduous dentition should focus on magnitude and severity as a guide to establishing strategies aimed at preventing occlusal problems later in life. ${ }^{1,2}$ Increased overjet, deep overbite, lateral crossbite and anterior open bite are the most common types of malocclusion in the primary dentition. ${ }^{3}$ Some malocclusions that arise at 3 years of age may improve over subsequent years (open bite), whereas others may worsen (distoclusion, lateral crossbite and unfavorable vertical occlusal conditions). ${ }^{3,4}$

Genetic factors, ethnic factors, nonnutritive sucking habits, impaired nasal breathing and functional atrophy of the maxilla due to the underdevelopment of dental arches are frequently associated with malocclusion. ${ }^{5-8}$ Few epidemiological surveys have addressed the primary dentition and even fewer studies have associated malocclusion with socioeconomic indicators. Investigations of this type are important for the allocation of public funds for health services. Previous studies have generally evaluated only one type of malocclusion and one socioeconomic indicator. ${ }^{6,9}$

The World Health Organization recommends periodic surveys of the 
main oral health problems. Epidemiological studies on malocclusion are important in identifying occlusal changes during growth and in determining the distribution of oral health conditions in a population. ${ }^{1,10}$ Moreover, malocclusion can exert an impact on a child's quality of life. ${ }^{3,11}$

Considering the scarcity of such investigations, the aim of the present study was to determine the prevalence of malocclusion and associations with socioeconomic indicators among preschoolers in Brazil.

\section{Methodology Sample}

A cross-sectional study was conducted with 732 children 3 to 5 years of age, enrolled at 33 (15 private and 18 public) preschools in the city of Campina Grande, Brazil. The participants were selected from a total population of 12,705 children in this age group (corresponding to $6.6 \%$ of the population).

A two-phase sampling method was used to ensure representativeness:

1. random selection of preschools from each health district (18 of 127 public schools and 15 of 122 private schools selected by lots); and

2. random selection of children from each preschool.

The sample size was calculated considering a $4 \%$ margin of error, 95\% confidence level and 50.0\% prevalence rate of malocclusion. A correction factor of 1.2 was applied to compensate for the design effect. The minimum sample size was estimated at 720 schoolchildren, to which $20 \%$ was added to compensate for possible losses, totaling 864 preschoolers.

This study received the approval of the Human Ethics Research Committee of the Universidade Estadual da Paraíba - UEPB (00460133000-11). All parents/guardians received information regarding the objectives, and signed terms of informed consent.

\section{Eligibility criteria}

Inclusion criteria:

- age 3 to 5 years;

- exclusively in the primary dentition phase;

- no loss of mesiodistal diameter due to caries;
- no previous orthodontic treatment;

- agreement to participate in the clinical exam.

\section{Training and calibration exercise}

The theoretical phase involved a discussion of diagnostic criteria for malocclusion and an analysis of photographs. A specialist in orthodontics was the gold standard in the theoretical framework and coordinated this step, instructing three dentists on how to perform the exam. The clinical phase was performed in a randomly selected preschool outside the main sample. Each dentist examined 50 children and interexaminer agreement was tested. Thirty children were reexamined after a seven-day interval to determine intraexaminer agreement. Kappa coefficients were 0.85 and 0.90 for interexaminer and intraexaminer agreement, confirming that the examiners were able to perform the epidemiological study. ${ }^{12}$

\section{Pilot study}

A pilot study was conducted to test the methodology. The children in the pilot study $(\mathrm{n}=40)$ were not included in the main sample. The results revealed no misunderstandings regarding the questionnaire or need to change the method.

\section{Non-clinical data collection}

Parents answered a questionnaire on sociodemographic data (mother's schooling and monthly household income). Income was dichotomized based on the Brazilian minimum wage (= US\$ 312.50).

\section{Clinical data collection}

The exams were performed at the selected preschools in the knee-to-knee position, aided by a portable lamp attached to the examiner's head $\left(\right.$ Petzl $^{\circledR}$, Clearfield, USA). Individual cross-infection protection equipment was used. Packaged and sterilized disposable mouth mirrors (Prisma ${ }^{\circledR}$, São Paulo, Brazil) and WHO probes (Trinity ${ }^{\circledR}$, Campo Mourão, Brazil) were used.

The clinical examination recorded aspects of overbite, overjet and crossbite using criteria recommended by Foster and Hamilton ${ }^{13}$ and Grabowski et al., ${ }^{3}$ which have been used by other authors. ${ }^{14}$ Horizontal overlap of the incisors was considered 
overjet. The measurement (in millimeters) was performed with the teeth in centric occlusion and the probe positioned parallel to the occlusal plane. No distance between upper and lower incisors was defined as normal overjet $(0 \mathrm{~mm})$; increased overjet was recorded when the distance was $>2 \mathrm{~mm}$, and anterior crossbite was recorded when the distance was $<0 \mathrm{~mm} .{ }^{13}$ Anterior crossbite was recorded when the lower incisors were observed in front of the upper incisors. ${ }^{13}$ Anterior open bite was recorded in the absence of contact between anterior teeth when posterior teeth were in occlusion. ${ }^{13}$ Normal overbite was defined when upper incisors overlapped lower incisors by $2 \mathrm{~mm}$. Overbite greater than $2 \mathrm{~mm}$ was designated deep overbite. ${ }^{3}$ Posterior crossbite was recorded when upper primary molars were occluded in lingual relationship to lower primary molars in centric occlusion. ${ }^{13}$ The participant was diagnosed with malocclusion when exhibiting at least one of the aforementioned conditions. ${ }^{3}$

\section{Statistical analysis}

Descriptive statistics were performed to describe the prevalence of malocclusion and characterize the sample. Bivariate Poisson regression (PR) was used to test associations between outcome (malocclusion) and independent variables (age, sex, and socioeconomic variables; $p<0.05)$. Statistical analysis was conducted using the Statistical Package for Social Sciences (SPSS for Windows, version 18.0 SPSS Inc., Chicago, USA).

\section{Results}

A total of 732 pairs of parents/guardians and children participated in the present study, corresponding to $84.72 \%$ of the total sample selected $(\mathrm{n}=864)$. The loss of 132 children $(15.28 \%)$ was attributed to absence from preschool more than three times on the days scheduled for the clinical exams $(n=76)$ and lack of cooperation during the exam $(\mathrm{n}=56)$.

The prevalence of malocclusion was $62.4 \%$. A total of $42.6 \%$ of the children had increased overjet, $2.2 \%$ had anterior crossbite, $19.3 \%$ had deep overbite, $21 \%$ had anterior open bite and $11.6 \%$ had posterior crossbite. Among the last group named, 94.1\% had unilateral posterior crossbite (Table 1).
Males, children four years of age, those who attended public school and those whose parents reported an income of 1 minimum wage or less accounted for the highest percentages of the sample (Table 2).

Age was the only variable significantly associated with malocclusion, more prevalent among 3-yearolds $(\mathrm{PR}=1.116$; 95\%CI: 1.049-1.187; Table 3).

\section{Discussion}

The prevalence of malocclusion in the deciduous dentition was high in the present study (62.4\%). Previous investigations report rates ranging from $36.46 \%$ to $87.0 \%$ in Brazilian studies ${ }^{14-17}$

Table 1 - Prevalence of malocclusion and types of malocclusion in 3-5-year-old children.

\begin{tabular}{c|c|c}
\hline Variables & $\mathrm{n}$ & $\%$ \\
\hline Increased overjet & 312 & 42.6 \\
\hline Anterior crossbite & 16 & 2.2 \\
\hline Deep overbite & 141 & 19.3 \\
\hline Anterior open bite & 154 & 21.0 \\
\hline Posterior crossbite (94.1\% unilateral) & 85 & 11.6 \\
\hline Presence of malocclusion & 457 & 62.4 \\
\hline
\end{tabular}

Table 2 - Sample characteristics related to socioeconomic indicators.

\begin{tabular}{|c|c|c|}
\hline Variable & $n$ & $\%$ \\
\hline \multicolumn{3}{|c|}{ Age (years) } \\
\hline 3 & 230 & 31.4 \\
\hline 4 & 341 & 46.6 \\
\hline 5 & 161 & 22.0 \\
\hline \multicolumn{3}{|c|}{ Sex } \\
\hline Male & 384 & 52.5 \\
\hline Female & 348 & 47.5 \\
\hline \multicolumn{3}{|c|}{ Type of preschool } \\
\hline Private & 353 & 48.2 \\
\hline Public & 379 & 51.8 \\
\hline \multicolumn{3}{|c|}{ Income } \\
\hline$\leq 1$ minimum wage & 368 & 50.3 \\
\hline$>1$ minimum wage & 364 & 49.7 \\
\hline Total & 732 & 100.0 \\
\hline
\end{tabular}


Table 3 - Bivariate Poisson regression of malocclusion and socioeconomic variables.

\begin{tabular}{|c|c|c|c|c|}
\hline \multirow{2}{*}{ Variable } & \multicolumn{2}{|c|}{ Malocclusion } & \multicolumn{2}{|r|}{ PR } \\
\hline & Present n (\%) & Absent n (\%) & $p$-value ${ }^{(1)}$ & $(95 \% \mathrm{Cl})$ \\
\hline \multicolumn{5}{|c|}{ Sex } \\
\hline Female & $216(62.1)$ & $132(37.9)$ & \multirow{2}{*}{0.847} & 1.00 \\
\hline Male & $241(62.8)$ & $143(37.2)$ & & $1.004(0.962-1.049)$ \\
\hline \multicolumn{5}{|c|}{ Age (years) } \\
\hline 3 & $159(69.1)$ & 71 (30.9) & $0.001^{*}$ & $1.116(1.049-1.187)$ \\
\hline 4 & $215(63.0)$ & $126(37.0)$ & $0.017^{*}$ & $1.076(1.013-1.142)$ \\
\hline 5 & $83(51.6)$ & 78 (48.4) & & 1.00 \\
\hline \multicolumn{5}{|c|}{ Type of school } \\
\hline Public & $231(60.9)$ & $148(39.1)$ & \multirow{2}{*}{0.390} & 1.00 \\
\hline Private & $226(64.0)$ & $127(36.0)$ & & $1.019(0.976-1.064)$ \\
\hline \multicolumn{5}{|c|}{ Income } \\
\hline$\leq 1$ minimum wage & $222(60.3)$ & $146(39.7)$ & \multirow{2}{*}{0.237} & $1.026(0.983-1.072)$ \\
\hline$>1$ minimum wage & $235(64.6)$ & $129(35.4)$ & & 1.00 \\
\hline \multicolumn{5}{|c|}{ Mother's schooling } \\
\hline$\leq 8$ years & $202(62.9)$ & $119(37.1)$ & \multirow{2}{*}{0.806} & $1.005(0.963-1.050)$ \\
\hline$>8$ years & $255(62.0)$ & $158(38.0)$ & & 1.00 \\
\hline
\end{tabular}

(1) Bivariate Poisson regression; ${ }^{*}$ significant at a $5.0 \%$ level. and $26.06 \%$ to $74.7 \%$ in international studies. ${ }^{3,18,19}$ This divergence demonstrates that the prevalence of malocclusion can vary across countries/regions. The differences may also be explained by differences in the age groups analyzed, the diagnostic criteria and the nomenclature regarding malocclusion. This study eliminated the confounder effect of no loss of mesiodistal diameter due to caries by excluding children with this condition. ${ }^{7,14}$

Increased overjet was the most frequent type of malocclusion (42.6\%). Previous studies report rates ranging from $12.1 \%$ to $32 \% . .^{20,21}$ This difference is likely due to the cutoff point used for the diagnosis. In the present study, increased overjet was defined as $\geq 2 \mathrm{~mm}$, which is the same value used in other studies. ${ }^{3,4,10}$ However, a number of researchers use $\geq 3 \mathrm{~mm} .{ }^{22}$ This type of malocclusion does not self-correct with age, primarily due to the impact of persistent, newly formed functional factors that disrupt dentition development. ${ }^{3,4}$

Anterior open bite was the second most frequent type of malocclusion and is generally one of the most frequently diagnosed conditions in this age group
(3-5 years), with prevalence rates ranging from $6.0 \%$ to $27.9 \% .^{1,19,21,23}$ Anterior open bite has been reported to be associated with nonnutritive sucking habits, common in this phase of life. ${ }^{6,7,16,21,24}$ These habits may be related to cultural and economic differences across populations, ${ }^{7,25}$ which may influence the variability in results.

Deep overbite was the third most frequent type of malocclusion (19.3\%), in agreement with a previous survey using a similar methodology $(19.7 \%) .^{14}$ There are also reports of lower prevalence rates in Brazilian studies (7.0\% to $13.2 \%) .{ }^{20}$ In these studies, the diagnostic criterion was the "incisal tip of the lower central incisors touching the palate in centric occlusion", ${ }^{13}$ unlike the present study, in which an overbite greater than $2 \mathrm{~mm}$ was designated as deep bite. ${ }^{3}$ Prevalence rates in Germany are reported to range from $24.3 \%{ }^{4}$ to $33.2 \%{ }^{3}$ This divergence may be related to ethnic differences, insofar as Brazil has a considerable degree of racial miscegenation, ${ }^{7}$ unlike the German population.

Posterior crossbite is believed to be transferred from the deciduous to the permanent dentition and 
can have long-term effects on the growth and development of the teeth and jaws. ${ }^{25}$ This type of malocclusion has been associated with nonnutritive sucking habits, mouth breathing and hypertrophy of the adenoids and tonsils. ${ }^{5,21,26}$ Posterior crossbite was the fourth most common type of malocclusion diagnosed $(11.6 \%)$, with most cases occurring unilaterally $(94.1 \%)$. The literature reports rates ranging from $11.6 \%$ to $13.4 \% .^{3,14}$ In a national survey carried out in Brazil, the prevalence of posterior crossbite was $21.9 \%$, ranging from $10.1 \%$ to $25.3 \%$ among its different regions. ${ }^{20}$ Since Brazil is a large country with considerable climate differences, a cold, wet climate in some regions may favor the development of allergies and breathing difficulties, the consequences of which may be mouth breathing and malocclusion. ${ }^{27,28}$ Indeed, higher prevalence rates of this type of malocclusion (19.9\% to $25.3 \%$ ) have been reported in these regions. ${ }^{20}$ However, the city of Campina Grande is located in the northeastern region of the country, with a warm, humid climate, where allergies and breathing difficulties are less common.

Anterior crossbite was the least common type of malocclusion, in agreement with findings described in previous studies $(0.1 \%$ to $6.7 \%))^{3,14,21}$ The rate reported in a national survey was $2.8 \%$, ranging from $1.4 \%$ to $3.6 \%$ among the different regions. ${ }^{20}$

Age was the only variable associated with malocclusion, in agreement with findings reported in the literature. ${ }^{3,4,9,25}$ The greater prevalence of malocclusion at younger ages suggests self-correction over time. ${ }^{3,4}$ However, these findings should be viewed with some latitude, seeing that any type of occlusal abnormality was considered malocclusion; this could also be considered a limitation to the present study. A number of authors argue that anterior open bite is a type of malocclusion that regresses with age. ${ }^{3}$

Sex was not associated with malocclusion, as confirmed in previous studies. ${ }^{6,25}$ Whereas a number of authors argue that children with greater purchasing power and those whose mothers have a lower schooling level are more likely to develop malocclusion due to greater access to and frequency of pacifier use, ${ }^{29,30}$ no significant associations were found in the present study between socioeconomic indica- tors and malocclusion, in agreement with findings reported in previous studies. ${ }^{6,9}$ It seems that another factor unassociated to social class has occurred, namely the greater participation of women in the workforce, with a consequent reduction in breastfeeding and greater susceptibility to the adoption of nonnutritive sucking habits.,25 Moreover, genetic and environmental factors can affect children ${ }^{6}$ regardless of social class.

This study has limitations that should be considered, particularly the fact that the socioeconomic data were collected using a questionnaire, and that the information contained in the parents' report may display a degree of bias, especially with regard to household income.

The present study offers a profile of malocclusion in the primary dentition. Malocclusion is not dependent on socioeconomic indicators and should be investigated in all children, regardless of social class. Although the data suggests that malocclusion may decrease with age, and that self-correction is possible, it constitutes a public health problem, as can be seen in the high prevalence found in the present study. The prevention of malocclusion should be prioritized in public polices to avoid possible deleterious consequences to the permanent dentition. Moreover, the prevention of malocclusion is less costly than its treatment at an older age.

\section{Conclusion}

The prevalence of malocclusion in the primary dentition was high. Increased overjet and anterior open bite were the most common types. Malocclusion was significantly associated with age, but not with socioeconomic indicators.

\section{Acknowledgments}

This study was supported by the Universidade Estadual da Paraíba - UEPB and the following Brazilian funding agencies: Coordenação de Aperfeiçoamento de Pessoal de Nivel Superior (CAPES - Ministério da Educação), Fundação de Amparo à Pesquisa do Estado de Minas Gerais (FAPEMIG) and Conselho Nacional de Desenvolvimento Científico e Tecnológico (CNPq/471-790-2011/7). 


\section{References}

1. Almeida ER, Narvai PC, Frazão P, Guedes-Pinto AC. Revised criteria for the assessment and interpretation of occlusal deviations in the deciduous dentition: a public health perspective. Cad Saude Publica. 2008 Apr;24(4):897-904.

2. Petersen PE. The World Oral Health Report 2003: continuous improvement of oral health in the 21st century - the approach of the WHO Global Oral Health Programme. Community Dent Oral Epidemiol. 2003 Dec;31 Suppl 1:S3-23.

3. Grabowski R, Stahl F, Gaebel M, Kundt G. Relationship between occlusal findings and orofacial myofunctional status in primary and mixed dentition. Part I: Prevalence of malocclusions. J Orofac Orthop. 2007 Jan;68(1):26-37. English, German.

4. Berneburg M, Zeyher C, Merkle T, Möller M, Schaupp E, Göz G. Orthodontic findings in 4- to 6-year-old kindergarten children from southwest Germany. J Orofac Orthop. 2010 May;71(3):174-86. English, German.

5. Katz CR, Rosenblatt A, Gondim PP. Nonnutritive sucking habits in Brazilian children: effects on deciduous dentition and relationship with facial morphology. Am J Orthod Dentofacial Orthop. 2004 Jul;126(1):53-7.

6. Peres KG, Barros AJ, Peres MA, Victora CG. Effects of breastfeeding and sucking habits on malocclusion in a birth cohort study. Rev Saude Publica. 2007 Jun;41(3):343-50.

7. Heimer MV, Katz CR, Rosenblatt A. Non-nutritive sucking habits, dental malocclusions, and facial morphology in Brazilian children: a longitudinal study. Eur J Orthod. 2008 Dec;30(6):580-5.

8. Limme M. [The need of efficient chewing function in young children as prevention of dental malposition and malocclusion]. Arch Pediatr. 2010 Dec;17 Suppl 5:S213-9. French.

9. Vasconcelos FM, Massoni AC, Heimer MV, Ferreira AM, Katz CR, Rosenblatt A. Non-nutritive sucking habits, anterior open bite and associated factors in Brazilian children aged 30-59 months. Braz Dent J. 2011;22(2):140-5.

10. Frazão P, Narvai PC, Latorre MR, Castellanos RA. [Malocclusion prevalence in the deciduous and permanent dentition of schoolchildren in the city of São Paulo, Brazil, 1996]. Cad Saude Publica. 2002 Sep-Oct;18(5):1197-205. Portuguese.

11. Marques LS, Ramos-Jorge ML, Paiva SM, Pordeus IA. Malocclusion: esthetic impact and quality of life among Brazilian schoolchildren. Am J Orthod Dentofacial Orthop. 2006 Mar;129(3):424-7.

12. Altman DG. Practical statistics for medical research. 1st ed. London: Chapman and Hall; 1991. 611 p.

13. Foster TD, Hamilton MC. Occlusion in the primary dentition: study of children at 2 and one-half to 3 years of age. Br Dent J. 1969 Jan 21;126(2):76-9.

14. Carvalho AC, Paiva SM, Scarpelli AC, Viegas CM, Ferreira FM, Pordeus IA. Prevalence of malocclusion in primary dentition in a population-based sample of Brazilian preschool children. Eur J Paediatr Dent. 2011 Jun;12(2):107-11.
15. Frazão P, Narvai PC, Latorre MR, Castellanos RA. Are severe occlusal problems more frequent in permanent than deciduous dentition?. Rev Saude Publica. 2004 Apr;38(2):247-54.

16. Leite-Cavalcanti A, Medeiros-Bezerra PK, Moura C. [Breastfeeding, bottle-feeding, sucking habits and malocclusion in Brazilian preschool children]. Rev Salud Publica (Bogota). 2007 Apr-Jun;9(2):194-204. Portuguese.

17. Brasil. Ministério da Saúde. Secretaria de Atenção à Saúde. Secretaria de Vigilância em Saúde. Departamento de Atenção Básica. Coordenação Nacional de Saúde Bucal. SB Brasil 2003: condições de saúde bucal da população brasileira 2002-2003: resultados principais. Brasília (DF): Ministério da Saúde; 2005. [cited 2013 Jan 11]. Avaliable from: http://dtr2001. saude.gov.br/editora/produtos/livros/pdf/05_0053_M.pdf.

18. Dhar V, Jain A, Van Dyke TE, Kohli A. Prevalence of gingival diseases, malocclusion and fluorosis in school-going children of rural areas in Udaipur district. J Indian Soc Pedod Prev Dent. 2007 Apr-Jun;25(2):103-5.

19. Stahl F, Grabowski R. Malocclusion and caries prevalence: is there a connection in the primary and mixed dentitions?. Clin Oral Investig. 2004 Jun;8(2):86-90.

20. Brasil. Ministério da Saúde. Secretaria de Atenção à Saúde. Secretaria de Vigilância em Saúde. Departamento de Atenção Básica. Coordenação Nacional de Saúde Bucal da População Brasileira. SB Brasil 2010: pesquisa nacional de saúde bucal resultados principais. Brasília (DF): Ministério da Saúde; 2011 [cited 2013 Jan 20]. Available from: http://189.28.128.100/ dab/docs/geral/projeto_sb2010_relatorio_final.pdf.

21. Góis EG, Ribeiro-Júnior HC, Vale MP, Paiva SM, Serra-Negra JM, Ramos-Jorge ML, et al. Influence of nonnutritive sucking habits, breathing pattern and adenoid size on the development of malocclusion. Angle Orthod. 2008 Jul;78(4):647-54.

22. World Health Organization. Oral health survey: basic methods. 4th ed. Geneva: ORH/EPID; 1997. 66 p.

23. Karjalainen S, Rönning O, Lapinleimu H, Simell O. Association between early weaning, non-nutritive sucking habits and occlusal anomalies in 3-year-old Finnish children. Int J Paediatr Dent. 1999 Sep;9(3):169-73.

24. Katz CR, Rosenblatt A. Nonnutritive sucking habits and anterior open bite in Brazilian children: a longitudinal study. Pediatr Dent. 2005 Sep-Oct;27(5):369-73.

25. Macena MC, Katz CR, Rosenblatt A. Prevalence of a posterior crossbite and sucking habits in Brazilian children aged 18-59 months. Eur J Orthod. 2009 Aug;31(4):357-61.

26. Scavone-Júnior H, Ferreira RI, Mendes TE, Ferreira FV. Prevalence of posterior crossbite among pacifier users: a study in the deciduous dentition. Braz Oral Res. 2007 AprJun;21(2):153-8.

27. Emmerich A, Fonseca L, Elias AM, Medeiros UV. [The relationship between oral habits, oronasopharyngeal alterations, and malocclusion in preschool children in Vitória, 
Espírito Santo, Brazil]. Cad Saude Publica. 2004 MayJun;20(3):689-97. Portuguese.

28. Vázquez-Nava F, Quezada-Castillo JA, Oviedo-Trevino S, Saldivar-González AH, Sánchez-Nuncio HR, Beltrán-Guzmán FJ, et al. Association between allergic rhinitis, bottle feeding, non-nutritive sucking habits, and malocclusion in the primary dentition. Arch Dis Child. 2006 Oct;91(10):836-40.

29. Roig AO, Martínez MR, García JC, Hoyos SP, Navidad GL, Alvarez JC, et al. Factors associated to breastfeeding ces- sation before 6 months. Rev Lat Am Enfermagem. 2010 MayJun;18(3):373-80.

30. Sousa RLS, Lima RB, Florêncio Filho C, Lima KC, Diógenes AMN. Prevalência e fatores de risco da mordida aberta anterior na dentição decídua completa em pré-escolares na cidade de Natal/RN. Rev Dental Press Orthod Orthop Facial. 2007 Mar-Apr;12(2):129-38. 